\title{
A Study on Daylighting Performance Evaluation of Light Shelf based on the Spatial Form of Inclined Ceiling
}

\author{
Heangwoo Lee ${ }^{1}$, Janghoo $\mathrm{Seo}^{2}$ and Yongseong $\mathrm{Kim}^{3}$ \\ ${ }^{1}$ The Graduate School of Techno Design, Kookmin University, Jeongneung-dong, \\ Seongbuk-gu, Seoul, 136-702, Korea \\ ${ }^{2,3}$ School of Architecture / The Graduate School of Techno Design, Kookmin \\ University, Jeongneung-dong, Seongbuk-gu, Seoul, 136-702, Korea \\ Imoonup2001@nate.com, ${ }^{2}$ seojh@kookmin.ac.kr,3yongkim@kookmin.ac.kr
}

\begin{abstract}
As the lighting energy usage accounts for a big proportion of the tolal energy usage in buildings, there have been diverse researches and technologicat developments on solutions. As a solution to such a problem, light shelves as one of the lighting ystems have been researched after being recognized its efficiency. However, the existing researches on light shelves focused only on the variables of light shelves and failed to reflect the consideration on spatial form, which is a variable of indoor spaces. In this regard, this research aimed to establish basic sources for light shelve design by obtaining optumal values for light shelves based on the performance evaluation on light shelves or Dhclined ceiling, a kind of the spatial forms. The research results are as follows: 1)As, the spatial depth meeting the standard indoor lighting level of $400 \mathrm{~lx}$ is equall seen regardless of the establishment of light shelves, there are no improvements in effictent lighting performance but improvements in lighting performance when the maximum ceiling heigh of the inclined ceiling increases. 2) The indoor average lighting level is lower with the light shelves established in the spatial form of inclined ceiling, than without the light shelves, which is considered to be caused by the awnings of the light shelves. In addition, the increase in angle and the decrease in width tend to raise the averageindoor illuminance level by reducing the awning surface. 3) The increase in the angle of light shelves increases the reflective surface, and this is helpful to improve lighting performance, as the increased angle tends to raise the uniformity ratio of illuminance by growing the amount of light flowed deep into the indoor space. 4) The optimal standard for light shelves on inclined, considering the winter solstice and vernal/autumnal equinox, is the width of $0.3 \mathrm{~m}$ of active light shelves. This research is relevant as it established basic sources by conducting performance evaluation on light shelves in terms of the inclined ceiling form, winten solstice, and vernal/autumnal equinox. It is considered that further performance evaluations are required on various spatial forms.
\end{abstract}

Reywords: Spatial, Form, Light Shelf, Lighting Energy Performance Evaluation

\section{Introduction}

\subsection{The Purpose of the Study}

According to 2010 LUTRON Lighting Control System (Daylight Harvesting) Seminar, the lighting energy usage in buildings is relatively high in the U.S. and Korea at $28 \%$ and $22 \%$, respectively. In this regard, there is a growing importance of research and development on the solutions. Light shelf is considered one of the most efficient 
solutions for the light energy issues in buildings, and thus various studies have been conducted. However, none are based on information of the form of indoor space in which the resident is directly related, which may be a problem in lighting energy calculation and light shelf design.

Therefore, this study aims to establish basic data for light shelf design by analyzing light shelf performance evaluation during winter solstice and spring/ autumn equinox and producing the optimal plan for spaces with a sloped ceiling, which is a unique form of indoor space.

\subsection{The Method and Scope of the Study}

This research discovered the optimal standard for light shelves based on the performance evaluation of light shelves in the special form of indoor spaces, inclined ceiling, and conducted performance evaluation under the following process.

First, the research set the spatial depth and ceiling height on the spatial form of inclined ceiling and determined the position to measure the indoor lighting level.

Second, the research set the variables of performance evaluation such as width, angle, height and reflectivity of light shelves.

Third, the research conducted performance valuation of light shelves at winter solstice and vernal/autumnal equinox based on the selected environmental conditions and excluded the summer solstice due to the lack of space in this paper. In addition, this research used the illuminance analysis program, Radiance. Considering that a simulation program will be appropriate to reflect various variables and spatial forms of light shelves.

\section{Set up of Light shelf and Ihclined Ceiling for Performance Evaluation 2.1. Setup of Inclined Ceiling}

In terms of setting the spatial forms for performance evaluation, as indicated in Table 1, the spaces sized $3 \mathrm{~m}$ (width) X $3 \mathrm{~m}$ (depth) X 2.5 (height) and $3 \mathrm{~m}$ (width) X $6 \mathrm{~m}$ (depth) X 2.5(height) were set as the basic unt space for inclined ceiling and the spaces with increasing ceiling beights from $2.6 \mathrm{~m}$ to $3.2 \mathrm{~m}$ by $0.3 \mathrm{~m}$ were set as indoor spatial forms. In addition, the spatial reflectivity for indoors was each set at $74.99 \%, 55 \%, 25.1 \%$ for ceiling, wall and floor and the lighting windows sized $2.0 \mathrm{~m} \times 1.8 \mathrm{~m}$ were located at the center of the lighting surface.

The illuminance calculating location was set at the height of $0.75 \mathrm{~m}$ from the floor space based upon the height of the working space and relevant researches. In terms of the standard unit space for performance evaluation, as shown in the Figure 3, a total of 36 locations in six rows with an interval of $0.5 \mathrm{~m}$ in spatial depth from by six rows with an interval of $0.5 \mathrm{~m}$ in spatial width based on the lighting surface to calculate il uminance. In addition, the study increased 36 points to calculate illuminance in terms of the lighting performance evaluation of lighting shelves depending on the spatial depth of $6 \mathrm{~m}$. The study calculated and analyzed illuminance based on the average illuminance of the areas ranging from the row of Y2 that is directly affected by light shelves to the row of Y5 to analyze the lighting performance of light shelves with different spatial depth, and applied values of all points including the rows of Y1 and Y6 to calculate uniformity ratio of illuminance [14]. 


\section{Table 1. Setup of Inclined Ceiling}

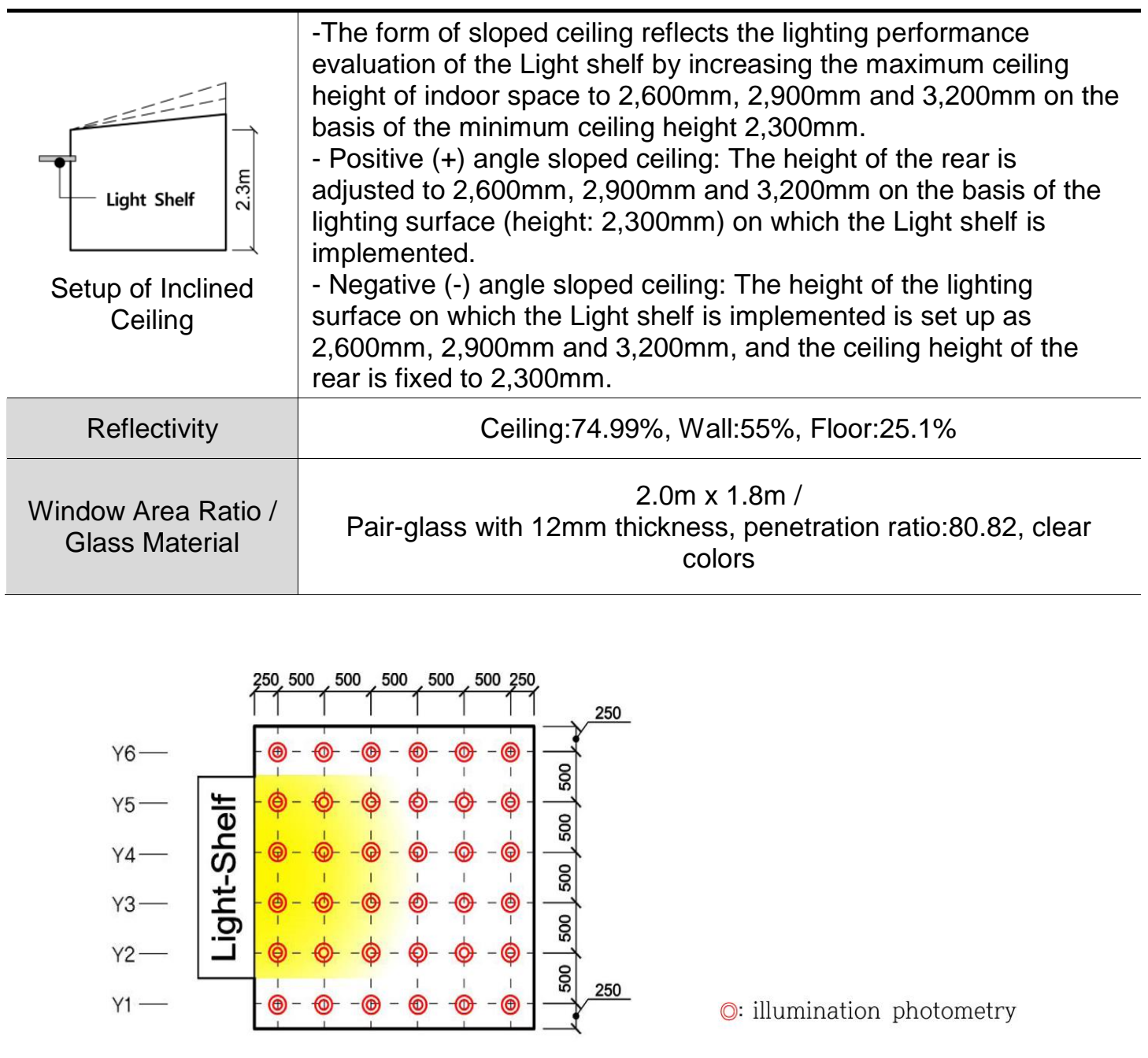

Figure 1. Ilumination Photometry for Light Shelf's Performance Evaluation [7]

\subsection{Setup of Light Shelf}

The variables of light shelves for performance evaluation was set as demonstrated in Table 2 based on the relevant researches on light shelf performance evaluation. In particular this study limited the types of light shelves to external shelf type.

Table 2. Setup of Depth of Space and Light Shelf

\begin{tabular}{l|l|l|l}
\hline Height & $1.8 \mathrm{~m}$ & Angle & $-10^{\circ}, 0^{\circ}, 10^{\circ}, 20^{\circ}, 30^{\circ}$ \\
Width & $0.3 \mathrm{~m}, 0.6 \mathrm{~m}, 0.9 \mathrm{~m}$ & Reflectivity & $85.77 \%$ \\
\hline
\end{tabular}




\section{Performance Evaluation of Light shelf for Inclined Ceiling}

\subsection{Performance Evaluation for Light Shelf}

Performance evaluation analysis method according to sloped ceiling and light shelf Performance evaluation analysis method according to sloped ceiling and light shelf is as follows. [7]

First, for performance evaluation by the variables of sloped ceiling and light shelf, this study calculated the illumination value obtained by the variables set up above, and deducted the spatial depth satisfying the standard illumination of 400lux in visual operation. Moreover, this study conducted the lighting performance evaluation of the light shelf by deducting the average illumination and uniformity ratio of illumination.

Second, as this study limited the scope to the form of sloped ceiling, there is no difference in the awning area and reflection area according to changes in indoor spatial form, while the awning area shows difference according to the variable of the light shelf. The awning area and reflection area are also related to the uniformity ratio of illumination in indoor space as well as the quantity of light flowing in, and thereby they are considered inportant elements. Therefore, this study deducted the awning area according to the light shelf variable and used it as the analytic data for the light shelf performance evaluation.

Third, this study drew the image of the process of the inflow and reflection of lights by light shelves and used it as a material to analyze the performance evaluation of light shelves.

\subsection{Light Shelf Performance Evaluation based on the Inclined Ceiling during Winter Solstice}

The performance evaluation depending on the inclined ceiling form and variables of light shelves at winter solstice resulted in as follows:

First, as the spatial depth in inclined ceiling with $3 \mathrm{~m}$ depth that satisfies the standard illuminance with or withou dight shelves established, regardless of the ceiling height, appears to be the same as $3 \mathrm{~m}$ an winter solstice, it is considered that there is no effects to reduce lighting energy through light shelves In addition, the spatial depth in the form of inclined ceiling with $6 \mathrm{~m}$ depth that satisfies the standard illuminance without light shelves established appears to be $5.75 \mathrm{~m}$, regardless of the indoor ceiling height of $2.45 \mathrm{~m}, 2.6 \mathrm{~m}$ and $2.75 \mathrm{~m}$. The depth of the space is equall demonstrated as $3.75 \mathrm{~m}$ to $5.75 \mathrm{~m}$ according to the width and changes of the angles in establishing light shelves on the indoor ceilings with $2.45 \mathrm{~m}, 2.6 \mathrm{~m}$ and $2.75 \mathrm{~m}$ height. Therefore, it is regarded that there are no effects of reducing lighting energy. In terms of the inclined ceilings, the increase in ceiling height and width of light shelves turns up to be inappropriate as the spatial depth that satisfies standard illuminance reduces, while the rise in the angle of light shelves is suitable to reduce the energy by increasing the spatial depth that satisfies the standard illuminance.

Second the average indoor illuminance is lower when the light shelve were established in the inclined ceiling than without light shelves at winter solstice, which is determined by the impacts of light shelves on awning. In addition, the increase in the angle of light shelves with decreasing awning surface tends to improve the average indoor illuminance, and the increase in the width of light shelves with increasing awning surface reduces the average indoor illuminance.

Third, in terms of the space in the form of inclined ceilings at winter solstice, the awning surface shrink as the angle of light shelves rises, and the uniformity ratio of illuminance tends to go down due to the low altitude during winter solstice as it failed to prevent lights with high altitude directly flowing into the indoor. In particular, the uniformity ratio of illuminance 
goes down when establishing light shelves of 30 degree which is because that the awning and reflective surface by above-mentioned light shelve are analyzed smaller than the angles of other light shelves.

Fourth, when it comes to the inclined ceiling at winter solstice, the appropriate standard of light shelves is drawn as $300 \mathrm{~mm}$ in width and angle of $10^{\circ}$ given the energy reduction and uniformity ratio of illuminance regardless of ceiling height.

\section{Table 3. Shaded Area and Reflection Area based on the Width and Angle of Light Shelf during Winter Solstice [14]}

\begin{tabular}{|c|c|c|}
\hline \multicolumn{2}{|c|}{ Light Shelf } & \multirow{2}{*}{ Shaded area $\left(\mathrm{m}^{2}\right)$} \\
\hline width $(m)$ & angle & \\
\hline \multirow{5}{*}{$0.3 / 0.6 / 0.9$} & $-10^{\circ}$ & $0.775 / 1.550 /$ \\
\hline & $0^{\circ}$ & \\
\hline & $10^{\circ}$ & \\
\hline & $20^{\circ}$ & 3 \\
\hline & $30^{\circ}$ & $0.011 / 0.021 / 0.032$ \\
\hline width (m) & angle & ection area $\left(m^{2}\right)$ \\
\hline \multirow{4}{*}{$0.3 / 0.6 / 0.9$} & & $0.600 / 1.200 / 1.767$ \\
\hline & & $0.600 / 1.200 / 1.800$ \\
\hline & & $0.600 / 1.200 / 1.800$ \\
\hline & & $0.000 / 0.000 / 0.000$ \\
\hline
\end{tabular}

\subsection{Light Sheli Perfornance Evaluation based on the Inclined Ceiling during Vernal/Autummal Equir ox}

The performance evaluation by the form of inclined ceiling and variables of light shelves at vernal/autumnal equinex resulted in as follows:

First, the form of inclined ceiling and $3 \mathrm{~m}$ in spatial depth turned out to equally have a depth of $3 \mathrm{~m}$ for the space that satisfies the standard illuminance when establishing or not establishing the light shelves regardless of ceiling height. Therefore, it is considered that there are no reducing effects of lighting energy through the light shelves. In addition, the form of the inclined ceiling and spatial depth of $6 \mathrm{~m}$, the spatial depth that satisfies the standard illuminance without light shelves is $3.75 \mathrm{~m}$ regardless of the indoor ceiling height of $2.45 \mathrm{~m}$, $2.6 \mathrm{~m}$ and $2.75 \mathrm{~m}$ and $2.75 \mathrm{~m}-3.75 \mathrm{~m}$ depending on the width and angle of light shelves established on the ceiling at the height of $2.45 \mathrm{~m}, 2.6 \mathrm{~m}$ and $2.75 \mathrm{~m}$. Therefore, there will be no reduction efficiency of lighting energy. In addition, in terms of the inclined ceiling with (+) degree angle, the increase in ceiling height and the width of light shelves often caused reduction in the spatial depth that satisfies standard illumination while the increase in light shelves deepened the spatial depth that satisfies the standard illuminance, which is regarded as appropriate to reduce energy. 
Second, the average indoor illuminance is lower when established light shelves in the space in the form of inclined ceiling than without light shelves at vernal/autumnal equinox. This is considered to be influenced by awning of light shelves. In addition, the increase in the angle of light shelves with decreasing awning surface tends to increase the average indoor illuminance, and the increase in the width of light shelves with increasing awning surface decreases the average indoor illuminance.

Third, in terms of the spaces in the form of inclined ceilings at vernal/autumnal equinox, as the angle of light shelves goes up, the reflective surface and depth of light inflow grows, resulting in the growth of the uniformity ratio of illuminance.

Fourth, the inclined ceiling at vernal/autumnal equinox, the proper standard of light shelves considering energy reduction and uniformity ratio of illuminance regardless of ceiling height is lower than $600 \mathrm{~mm}$ in width and at $20^{\circ}$. As shown in Table 7 , as the light directly flows into through the reflective surface of light shelves rather than the reflection between reflective surface and ceiling surface of the shelves, the $30^{\circ}$ light shelves is improper.

Table 4. Shaded Area and Reflection Area based on the Width and Angle of Light Shelf during Spring Equinox and Autumn Equinox

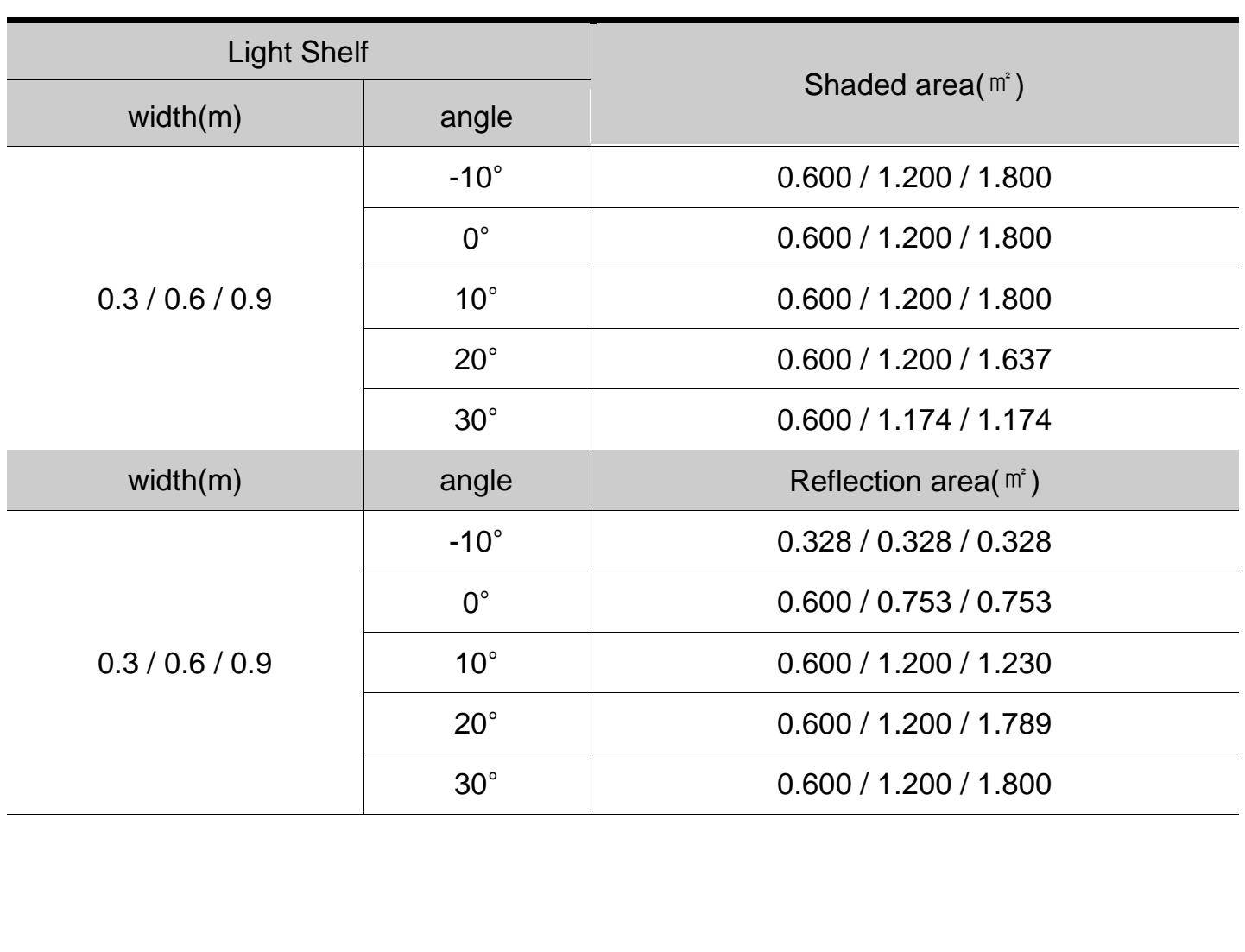


Table 5. Light Shelf Performance Evaluation based on the Inclined Ceiling During Winter Solstice (Depth: 3m /6m)[14]

\begin{tabular}{|c|c|c|c|c|c|c|c|c|c|c|}
\hline \multicolumn{11}{|c|}{ Depth : 3m } \\
\hline & & \multicolumn{3}{|c|}{ Ceiling height $2450 \mathrm{~mm}$} & \multicolumn{3}{|c|}{ Ceiling height $2600 \mathrm{~mm}$} & \multicolumn{3}{|c|}{ Ceiling height $2750 \mathrm{~mm}$} \\
\hline \multicolumn{2}{|c|}{ L. S. } & \multirow{2}{*}{ S.I. (m) } & \multirow{2}{*}{ A.I. (lux) } & \multirow{2}{*}{ U.F. } & \multirow{2}{*}{ S.I. (m) } & \multirow{2}{*}{ A.I. (lux) } & \multirow{2}{*}{ U.F } & \multirow{2}{*}{ S.I. (m) } & \multirow{2}{*}{ A.I. (lux) } & \multirow{2}{*}{ U.F. } \\
\hline W & $A$ & & & & & & & & & \\
\hline \multicolumn{2}{|c|}{$\mathrm{N}$} & 3.00 & 18394 & 0.054 & 3.00 & 18336 & 0.053 & 3.00 & 18277 & 0.050 \\
\hline \multirow{5}{*}{0.3} & -10 & 3.00 & 15587 & 0.068 & 3.00 & 15533 & 0.065 & 3.00 & 15484 & 0.063 \\
\hline & 0 & 3.00 & 15619 & 0.067 & 3.00 & 15556 & 0.063 & 3.00 & 15517 & 0.063 \\
\hline & 10 & 3.00 & 15639 & 0.065 & 3.00 & 15565 & 0.063 & 3.00 & 15517 & 0.061 \\
\hline & 20 & 3.00 & 18375 & 0.056 & 3.00 & 17892 & 0.049 & 3.00 & 18268 & 0.051 \\
\hline & 30 & 3.00 & 18352 & 0.053 & 3.00 & 18289 & 0.052 & 3.00 & & 0.049 \\
\hline \multirow{5}{*}{0.6} & -10 & 3.00 & 12759 & 0.077 & 3.00 & 12703 & 0.076 & 3.00 & 12641 & 0.074 \\
\hline & 0 & 3.00 & 15553 & 0.069 & 3.00 & 15491 & 0.067 & 3.0 & 15432 & 0.063 \\
\hline & 10 & 3.00 & 15604 & 0.067 & 3.00 & 1 & 0.063 & 3.0 & 15467 & 0.062 \\
\hline & 20 & 3.00 & 15596 & 0.064 & 3.00 & & 0.062 & 3.00 & 15489 & 0.060 \\
\hline & 30 & 3.00 & 18310 & 0.053 & 3.00 & 88 & 50 & 3.00 & 18213 & 0.049 \\
\hline \multirow{5}{*}{0.9} & -10 & 3.00 & 9877 & 0.089 & 3.00 & 9830 & 0.089 & 3.00 & 9779 & 0.089 \\
\hline & 0 & 3.00 & 12732 & 0.07 & . & 3 & 0.075 & 3.00 & 12596 & 0.074 \\
\hline & 10 & 3.00 & 15540 & 0.06 & 3.00 & 15475 & 0.064 & 3.00 & 15408 & 0.062 \\
\hline & 20 & 3.00 & 15571 & & 3.00 & 15510 & 0.061 & 3.00 & 15454 & 0.060 \\
\hline & 30 & 3.00 & 18294 & 052 & 3.00 & 18245 & 0.050 & 3.00 & 18197 & 0.050 \\
\hline \multicolumn{11}{|c|}{ Dêpth $6 \mathrm{~m}$} \\
\hline$w$ & A & \multicolumn{3}{|c|}{ Ceiling height $2450 \mathrm{~mm}$} & \multicolumn{3}{|c|}{ Ceiling height $2600 \mathrm{~mm}$} & \multicolumn{3}{|c|}{ Ceiling height $2750 \mathrm{~mm}$} \\
\hline \multicolumn{2}{|c|}{$\mathrm{N}$} & 5.75 & 9488 & 0.04 & 5.75 & 9450 & 0.039 & 5.75 & 9412 & 0.039 \\
\hline \multirow{5}{*}{0.3} & -10 & 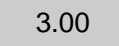 & 15587 & 0.068 & 3.00 & 15533 & 0.065 & 3.00 & 15484 & 0.063 \\
\hline & 0 & 300 & 15619 & 0.067 & 3.00 & 15556 & 0.063 & 3.00 & 15517 & 0.063 \\
\hline & & 3.00 & 15639 & 0.065 & 3.00 & 15565 & 0.063 & 3.00 & 15517 & 0.061 \\
\hline & 2 & 3.00 & 8375 & 0.056 & 3.00 & 17892 & 0.049 & 3.00 & 18268 & 0.051 \\
\hline & 30 & 3.00 & 18352 & 0.053 & 3.00 & 18289 & 0.052 & 3.00 & 18241 & 0.049 \\
\hline \multirow{10}{*}{0.6} & -10 & 3.00 & 12759 & 0.077 & 3.00 & 12703 & 0.076 & 3.00 & 12641 & 0.074 \\
\hline & 0 & 3.00 & 15553 & 0.069 & 3.00 & 15491 & 0.067 & 3.00 & 15432 & 0.063 \\
\hline & 10 & 3.00 & 15604 & 0.067 & 3.00 & 15525 & 0.063 & 3.00 & 15467 & 0.062 \\
\hline & & 3.00 & 15596 & 0.064 & 3.00 & 15541 & 0.062 & 3.00 & 15489 & 0.060 \\
\hline & & 3.00 & 18310 & 0.053 & 3.00 & 18268 & 0.050 & 3.00 & 18213 & 0.049 \\
\hline & -10 & 3.00 & 9877 & 0.089 & 3.00 & 9830 & 0.089 & 3.00 & 9779 & 0.089 \\
\hline & 0 & 3.00 & 12732 & 0.077 & 3.00 & 12659 & 0.075 & 3.00 & 12596 & 0.074 \\
\hline & 10 & 3.00 & 15540 & 0.067 & 3.00 & 15475 & 0.064 & 3.00 & 15408 & 0.062 \\
\hline & 20 & 3.00 & 15571 & 0.064 & 3.00 & 15510 & 0.061 & 3.00 & 15454 & 0.060 \\
\hline & 30 & 3.00 & 18294 & 0.052 & 3.00 & 18245 & 0.050 & 3.00 & 18197 & 0.050 \\
\hline
\end{tabular}

W: Width of Light shelf, A: Angle of Light shelf, N: Light shelf not installed, S.I.: Standard illuminance satisfaction degree(m), A.I.: Average illuminance, U.F.: Uniformity factor, his indicates lower score than the value estimated with no Light shelf installed, Bold: Ceiling value of uniformity factor 
International Journal of Smart Home Vol.8, No.4 (2014)

\section{Table 6. Inflow and Reflection of Light Based on the Inclined Ceiling During Winter Solstice (Depth: 3m /6m)[14]}

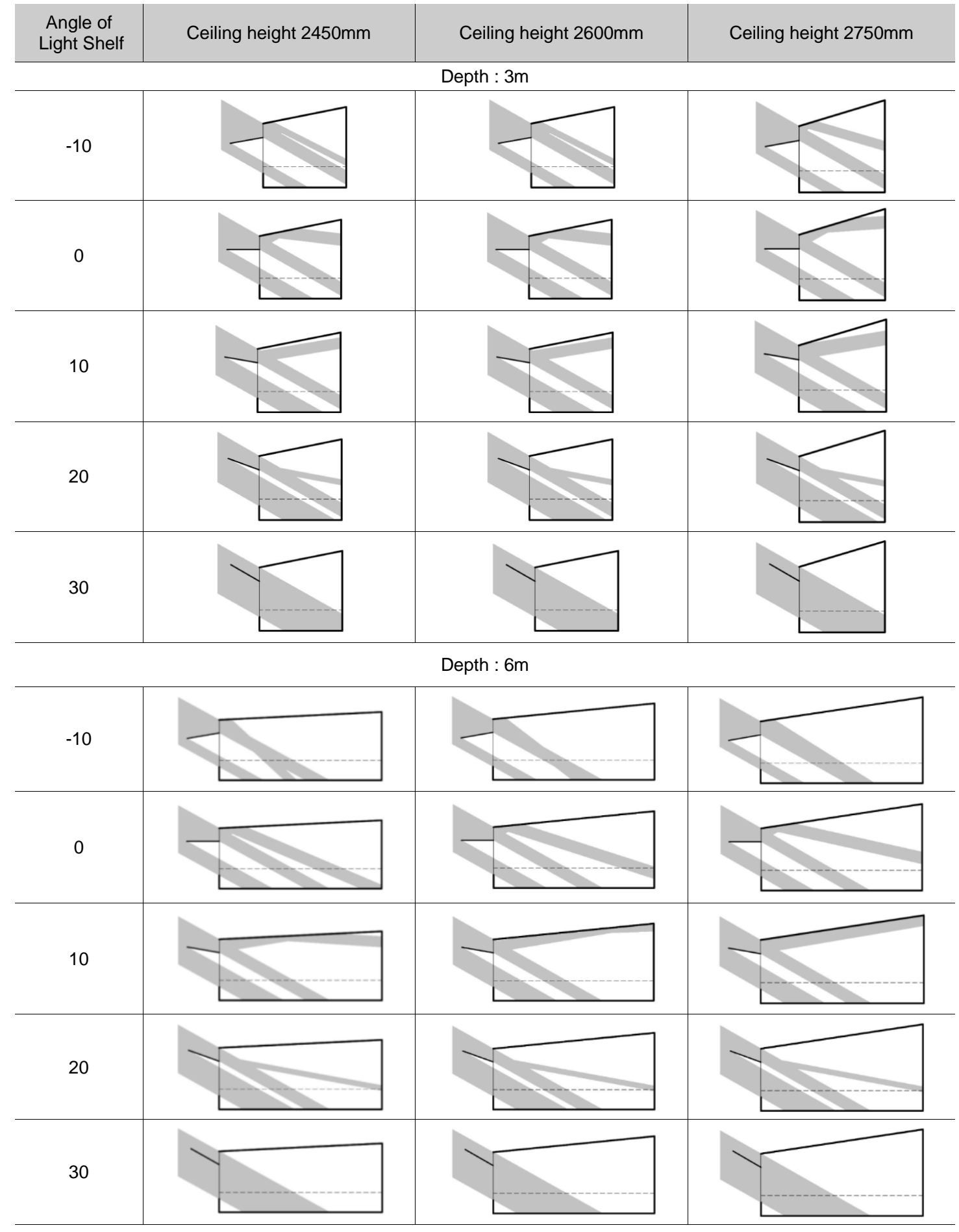

: Height of illumination photometry(750mm) 
Table 7. Light Shelf Performance Evaluation based on the Inclined Ceiling during Spring Equinox and Autumn Equinox (Depth: $3 \mathrm{~m} / 6 \mathrm{~m}$ )

\begin{tabular}{|c|c|c|c|c|c|c|c|c|c|c|}
\hline \multicolumn{11}{|c|}{ Depth : 3m } \\
\hline & & \multicolumn{3}{|c|}{ Ceiling height $2450 \mathrm{~mm}$} & \multicolumn{3}{|c|}{ Ceiling height $2600 \mathrm{~mm}$} & \multicolumn{3}{|c|}{ Ceiling height $2750 \mathrm{~mm}$} \\
\hline \multicolumn{2}{|c|}{ L. S. } & \multirow{2}{*}{ S.I. (m) } & \multirow{2}{*}{ A.I. (lux) } & \multirow{2}{*}{ U.F. } & \multirow{2}{*}{ S.I. (m) } & \multirow{2}{*}{ A.I. (lux) } & \multirow{2}{*}{ U.F } & \multirow{2}{*}{ S.I. (m) } & \multirow{2}{*}{ A.I. (lux) } & \multirow{2}{*}{ U.F. } \\
\hline W & A & & & & & & & & & \\
\hline \multicolumn{2}{|c|}{$\mathrm{N}$} & 3.00 & 18394 & 0.054 & 3.00 & 18336 & 0.053 & 3.00 & 18277 & 0.050 \\
\hline \multirow{5}{*}{0.3} & -10 & 3.00 & 6330 & 0.119 & 3.00 & 6273 & 0.117 & 3.00 & 6211 & 0.110 \\
\hline & 0 & 3.00 & 6366 & 0.119 & 3.00 & 6304 & 0.116 & 3.00 & 6245 & 0.117 \\
\hline & 10 & 3.00 & 6395 & 0.121 & 3.00 & 6322 & 0.119 & 3.00 & 6259 & 0.119 \\
\hline & 20 & 3.00 & 6404 & 0.124 & 3.00 & 6336 & 0.122 & 3.00 & 6263 & 0.122 \\
\hline & 30 & 3.00 & 6404 & 0.129 & 3.00 & 6333 & 0.128 & 3.00 & $<$ & 0.124 \\
\hline \multirow{5}{*}{0.6} & -10 & 3.00 & 1539 & 0.435 & 3.00 & 1478 & 0.440 & 3.00 & 1432 & 0.442 \\
\hline & 0 & 3.00 & 1603 & 0.437 & 3.00 & 1542 & 0.442 & 30 & 1471 & 0.445 \\
\hline & 10 & 3.00 & 6343 & 0.119 & 3.00 & 6267 & 0.116 & 3.00 & 6208 & 0.110 \\
\hline & 20 & 3.00 & 6364 & 0.122 & 3.00 & & 0.119 & 3.00 & 6227 & 0.117 \\
\hline & 30 & 3.00 & 6374 & 0.124 & 3.00 & 6302 & 0.125 & 3.00 & 6237 & 0.118 \\
\hline \multirow{5}{*}{0.9} & -10 & 3.00 & 1423 & 0.425 & 3.00 & 1367 & Q.427 & 3.00 & 1325 & 0.437 \\
\hline & 0 & 3.00 & 1502 & 0.420 & 3.00 & 1446 & 0.437 & 3.00 & 1378 & 0.435 \\
\hline & 10 & 3.00 & 1565 & 0.42 & 3.00 & 1489 & 0.445 & 3.00 & 1420 & 0.441 \\
\hline & 20 & 3.00 & 1598 & 0.4 & 3.00 & 1520 & 0.471 & 3.00 & 1453 & 0.467 \\
\hline & 30 & 3.00 & 6326 & 0.123 & 3.00 & 6252 & 0.117 & 3.00 & 6185 & 0.115 \\
\hline W & A & \multicolumn{6}{|c|}{ Ceiling height $2450 \mathrm{~mm}$ Cêlling height $2600 \mathrm{~mm}$} & \multicolumn{3}{|c|}{ Ceiling height $2750 \mathrm{~mm}$} \\
\hline \multicolumn{2}{|c|}{$\mathrm{N}$} & 5.75 & 9488 & 0.040 & 5.75 & 9450 & 0.039 & 5.75 & 9412 & 0.039 \\
\hline \multirow{5}{*}{0.3} & -10 & & 3290 & 0.045 & 3.25 & 3268 & 0.043 & 3.25 & 3253 & 0.045 \\
\hline & 0 & & 3321 & 0.042 & 3.75 & 3295 & 0.045 & 3.25 & 3270 & 0.045 \\
\hline & 11 & 3.75 & 3336 & 0.044 & 3.75 & 3311 & 0.047 & 3.75 & 3284 & 0.048 \\
\hline & 40 & 3.75 & 3348 & 0.047 & 3.75 & 3315 & 0.043 & 3.75 & 3296 & 0.048 \\
\hline & 30 & 3.75 & 3346 & 0.049 & 3.75 & 3320 & 0.051 & 3.75 & 3294 & 0.050 \\
\hline \multirow{10}{*}{0.6} & -10 & 3.25 & 885 & 0.141 & 3.25 & 864 & 0.150 & 3.25 & 850 & 0.150 \\
\hline & 0 & & 918 & 0.134 & 3.25 & 897 & 0.135 & 3.25 & 880 & 0.155 \\
\hline & 10 & 3.25 & 3291 & 0.041 & 3.25 & 3273 & 0.043 & 3.25 & 3253 & 0.045 \\
\hline & & 3.75 & 3318 & 0.046 & 3.25 & 3296 & 0.047 & 3.25 & 3270 & 0.048 \\
\hline & & 3.75 & 3331 & 0.049 & 3.75 & 3301 & 0.050 & 3.75 & 3277 & 0.051 \\
\hline & -10 & 3.25 & 815 & 0.138 & 3.25 & 791 & 0.137 & 3.25 & 786 & 0.153 \\
\hline & 0 & 3.25 & 867 & 0.147 & 3.25 & 837 & 0.151 & 3.25 & 829 & 0.151 \\
\hline & 10 & 3.25 & 895 & 0.141 & 3.25 & 869 & 0.153 & 3.25 & 855 & 0.162 \\
\hline & 20 & 3.25 & 922 & 0.155 & 3.25 & 900 & 0.157 & 3.25 & 871 & 0.173 \\
\hline & 30 & 3.75 & 3292 & 0.047 & 3.25 & 3266 & 0.054 & 3.25 & 3248 & 0.050 \\
\hline
\end{tabular}

W: Width of Light shelf, A: Angle of Light shelf, N: Light shelf not installed, S.I.: Standard illuminance satisfaction degree $(\mathrm{m})$, A.I.: Average illuminance, U.F.: Uniformity factor, : This indicates lower score than the value estimated with no Light shelf installed, Bold: Ceiling value of uniformity factor 
International Journal of Smart Home Vol.8, No.4 (2014)

\section{Table 8. Inflow and reflection of Light Based on the Inclined Ceiling during Spring Equinox and Autumn Equinox (Depth: $3 \mathrm{~m} / 6 \mathrm{~m}$ )}

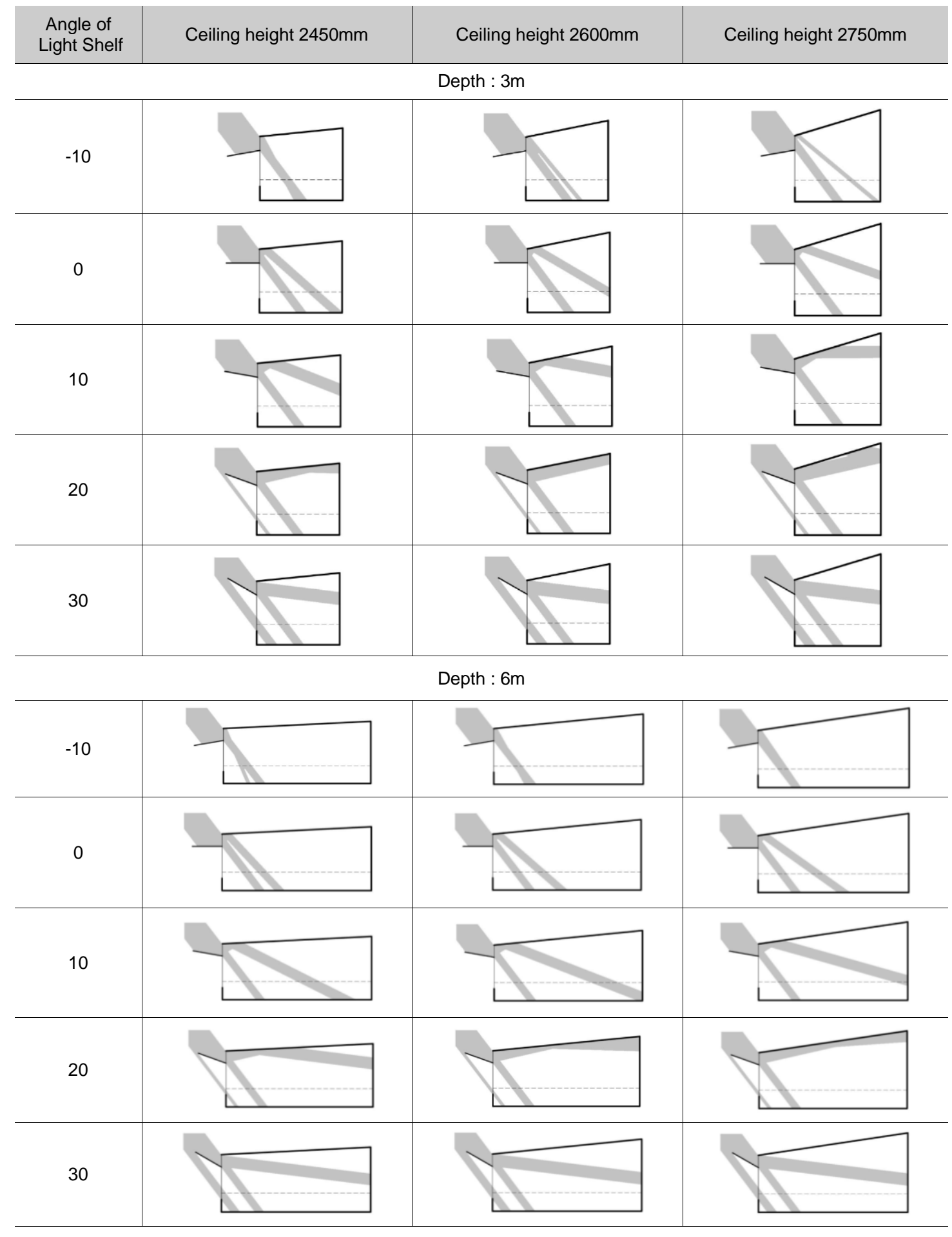

Height of illumination photometry $(750 \mathrm{~mm})$ 


\subsection{Discussion}

The results of performance evaluation of light shelves depending on the inclined ceiling are as follows:

First, as the form of inclined ceiling with the spatial depth of $3 \mathrm{~m}$ is equally demonstrated in $3 \mathrm{~m}$ spatial depth that satisfies the standard illuminance regardless of whether the light shelves were established at winter solstice and vernal/autumnal equinox, there is no reduction efficiency of lighting energy through light shelves. In addition, when it comes to the form of inclined ceilings with the spatial depth of $6 \mathrm{~m}$, there were no improvements the spatial depth that satisfies each standard illuminance at winter solstice and vernal/autumnal equinox about not established light shelves. Provided that while the increase in ceiling height and width of light shelves of inclined ceiling often decreases the spatial depth satisfying the standard illuminance, the rise in the angle of light shelves deepens the spatial depth to meet the standard illuminance, which is regarded as appropriate to improve lighting performance.

Second, the average indoor illuminance with light shelves established in the space in the form of inclined ceiling at winter solstice, vernal/autumnal equinox is lower than without light shelves established, which is considered to be influenced by the awnings of light shelves. In addition, the increase in the angle of light shelves with decreasing awning surface often raises the average indoor illuminance, and the increase in the width of light shelves with increasing awning surface reduces the average indoor illuminance.

Third, in terms of the form of inclined ceilingswinter solstice, vernal/autumnal equinox, as the angle of light shelves increases, the reflective surface and depth of light inflow grows that resulted in the growth of the uniformity ratio of illuminance.

Fourth, the optimal value for light shelves on inclined cellings given the depth that satisfies the standard illuminance and uniformity ratio of ibaminance is with $300 \mathrm{~mm}$ in width and an angle of $10^{\circ}$ at winter solstice and less than $600 \mathrm{~mm}$ in width and angle of $20^{\circ}$ at vernal/autumnal equinox. In the aspects that the light shelves are available to adjust the degree of angle under control, the active light shelves with the width of $300 \mathrm{~mm}$ are considered to be appropriate as shown in Table 9 at winter solstice and vernal/autumnal equinox.

Table 9. Optimal Standard of Light Shelf based on the Inclined Ceiling During Winter Solstice, Spring Equinox and Autumn Equinox

\begin{tabular}{c|c}
\hline solar term & Optimal standard of Light Shelf \\
\hline \hline winter solstice & width $300 \mathrm{~mm}$, angle $10^{\circ}$ \\
\hline spring equinox and autumn equinox & width $600 \mathrm{~mm} / 300 \mathrm{~mm}$, angle $20^{\circ}$ \\
\hline $\begin{array}{c}\text { winter solstice, spring equinox and } \\
\text { autumn equinox }\end{array}$ & width $300 \mathrm{~mm}$, Movable Light Shelf \\
\hline
\end{tabular}

\section{Conclusion}

This is a research to establish the basic sources for designing light selves, which are suggested as a solution to the lighting energy issue, conducted performance evaluation of light shelves depending on the spatial forms. The results are as follows: 
First, the depth that satisfies the average indoor illuminance at winter solstice, vernal/autumnal equinox is the same regardless of whether the light shelves are established. Therefore, there were no improvements in efficient lighting performance but it was analyzed to be favorable in improving lighting performance when the maximum ceiling height of the inclined ceiling increases.

Second, the average indoor illuminance with light shelves established in the space in the form of inclined ceiling at winter solstice, vernal/autumnal equinox is lower than without light shelves established, which is considered to be influenced by the awnings of light shelves. In addition, the increase in the angle of light shelves and the reduction of the width reduces the awning surface and tends to raise the average indoor illuminance.

Third, the increase in the angle of light shelves grows the reflective surface and the amount of light that was deeply came into indoors, and tends to improve the uniformity ratio of illuminance, showing that it is favorable to improve lighting performance.

Fourth, the optimal value for light shelves on inclined ceilings given winter solstice and vernal/autumnal equinox was concluded to be active light shelves with $0.3 \mathrm{~m}$ in depth.

This research is considered to be highly used as a basic resource in designing light shelves based on the performance evaluation on various spatial forms Provided that this research has limitations as it was conducted only for the inclined centing form, winter solstice and vernal/autumnal equinox, further performance evaluations should be conducted on light shelves for various spaces.

\section{References}

[1] S. K. Back and S. H. Le, "A Study on Lightng Design and llumination and Luminance of in Advanced type Control Room by the Standard of Ergonomics", Journal of the ergonomics society of Korea, vol. 27, no. 2, (2008).

[2] Y. G. Chung, "Daylighting Performance Evaluation of window Integrated Light Shelf System", Journal of the Korean Institute of EducationalAtchitecture and Environment, vol. 7, no. 5, (2007).

[3] S. Cko, "The Technical Development Status of Energy Convergence Building", Journal of the Architectural Institute of Korea Planning \& Design, vol. 55, no 2, (2009).

[4] S. Cko, "The Technical Development Status of Energy Convergence Building", Journal of the Architectural Institute of Korea Planning \& Design, vol 55, no. 2, (2009).

[5] S. P. Han, "A Study on Lighting Control Method for Harmonization of Daylighting and Artificial Lighting", Journal of the Architectural Institute of Korea Planning \& Design, vol. 26, no. 8, (2010).

[6] S. P. Han, "A Study on Light ng Control Method for Harmonization of Daylighting and Artificial Lighting", Journal of the Architecturat Institute of Korea Planning \& Design, vol. 26, no. 8, (2010).

[7] H. W. Lee, J. H. Seo, D S. Kim and Y. S. Kim, "Simulation Study on the Performance Evaluation of Lightshelf focused on the Depth of Space and the Dimensions and Angles of Light-shelf", Journal of the Architectural Instifute of Korea Planning \& Design, vol. 29, no. 3, (2013).

[8] T. W. Seo, H. W. Lee and Y. S. Kim, "Green Home IT Light-Shelf Survey Book 2012”, SISC, Korea, (2012).

[9] W. R. W. Chae, H. W. Lee and Y. S. Kim, "Green Home IT Louver System Survey Book 2013", SISC, Korea, (2012)

[10] T. J. Choi, "A Study on the Prediction of Energy Conservation in Apartment Building Utilization by lightself, Proceeding of the SAREK 2011 Summer Annual Conference, (2001).

[11] D. W Kim and C. S. Park, "Performance Assessment of Building Envelopes II: LightShlef, RetroLux", Proceeding of the KSES 2009 Spring Annual Conference, (2009).

[12] B. K. Kim and J. T. Kim, "Scale Model Experiment for Daylighting Performance by Lightshelf Types", Journal of the Korean Institute of Educational Architecture and Environment, vol. 9, (2005).

[13] J. T. Kim, "Design and Performance Evaluation of Horizontal Light-Redirecting Devices in Offices", Proceeding of the SAREK 2005 Summer Annual Conference, vol. 19, no. 3, (2005).

[14] B. C. Park, "An Fundamental Study on the Interactive System for Daylight Response Dimming System and Indoor Shading Systems", Proceeding of Annual Conference of the Architectural Institute of Korea Planning \& Design, vol. 27, no. 1, (2007).

[15] H. W. Lee, J. H. Seo and Y. S. Kim, "A Preliminary Study on Daylighting Performance Evaluation of Light Shelf based on the Inclined Ceiling during winter solstice", Architecture and Civil Engineering 2014, vol. 47, (2014). 


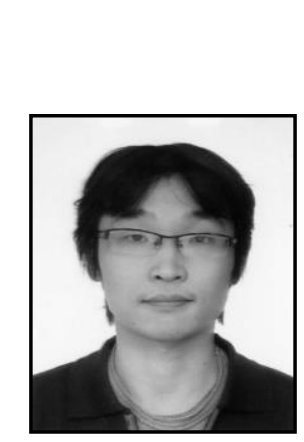

\section{Author}

Heangwoo Lee, Doctor candidate, Graduate School of Techno Design Department of Architectural Design, Kookmin University, Researcher, Smart Home Industrialization Support Center by the Ministry of Trade, Industry \& Energy, Researcher, Institute of Techo Design, Kookmin University.

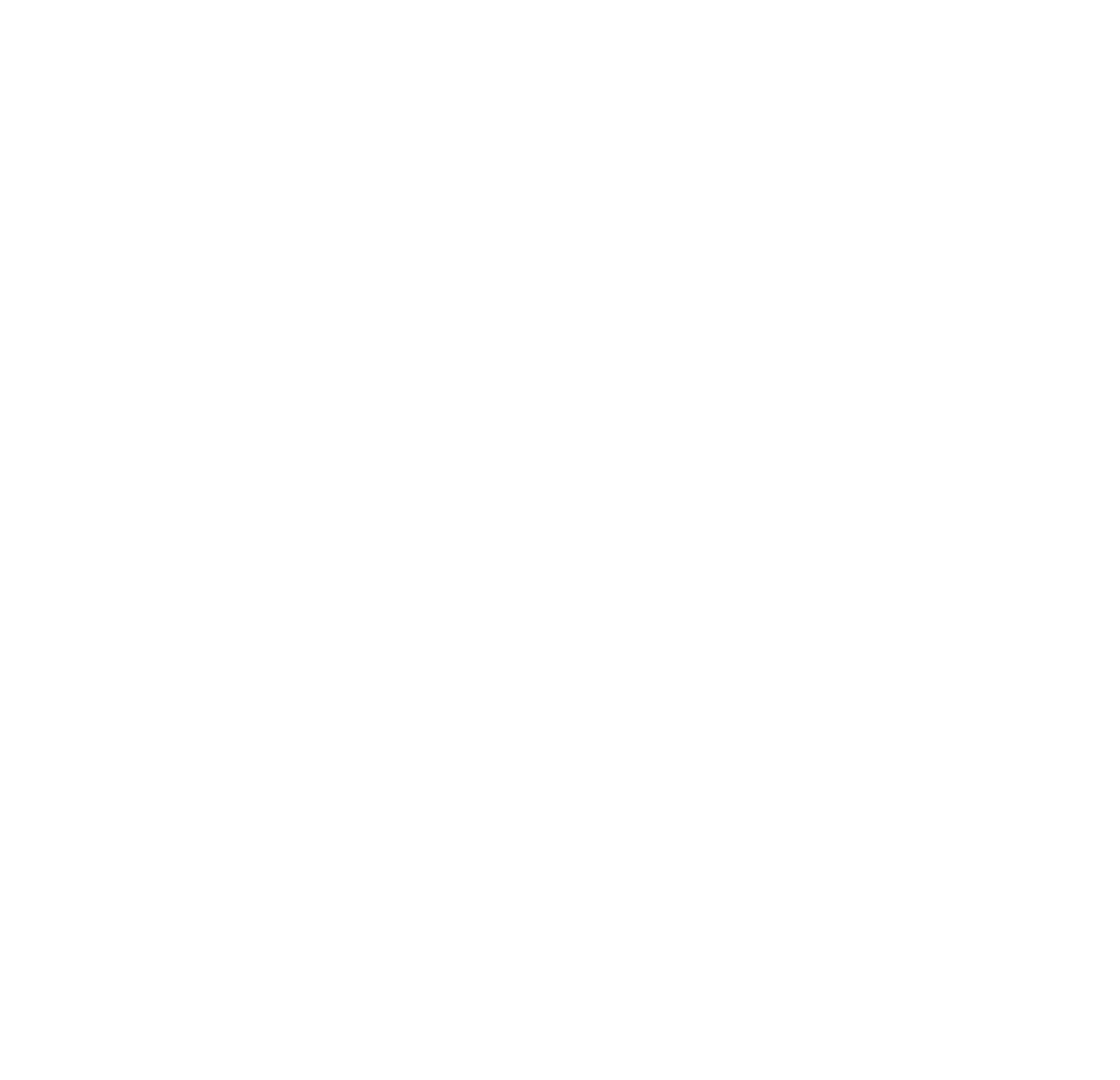


International Journal of Smart Home

Vol.8, No.4 (2014)

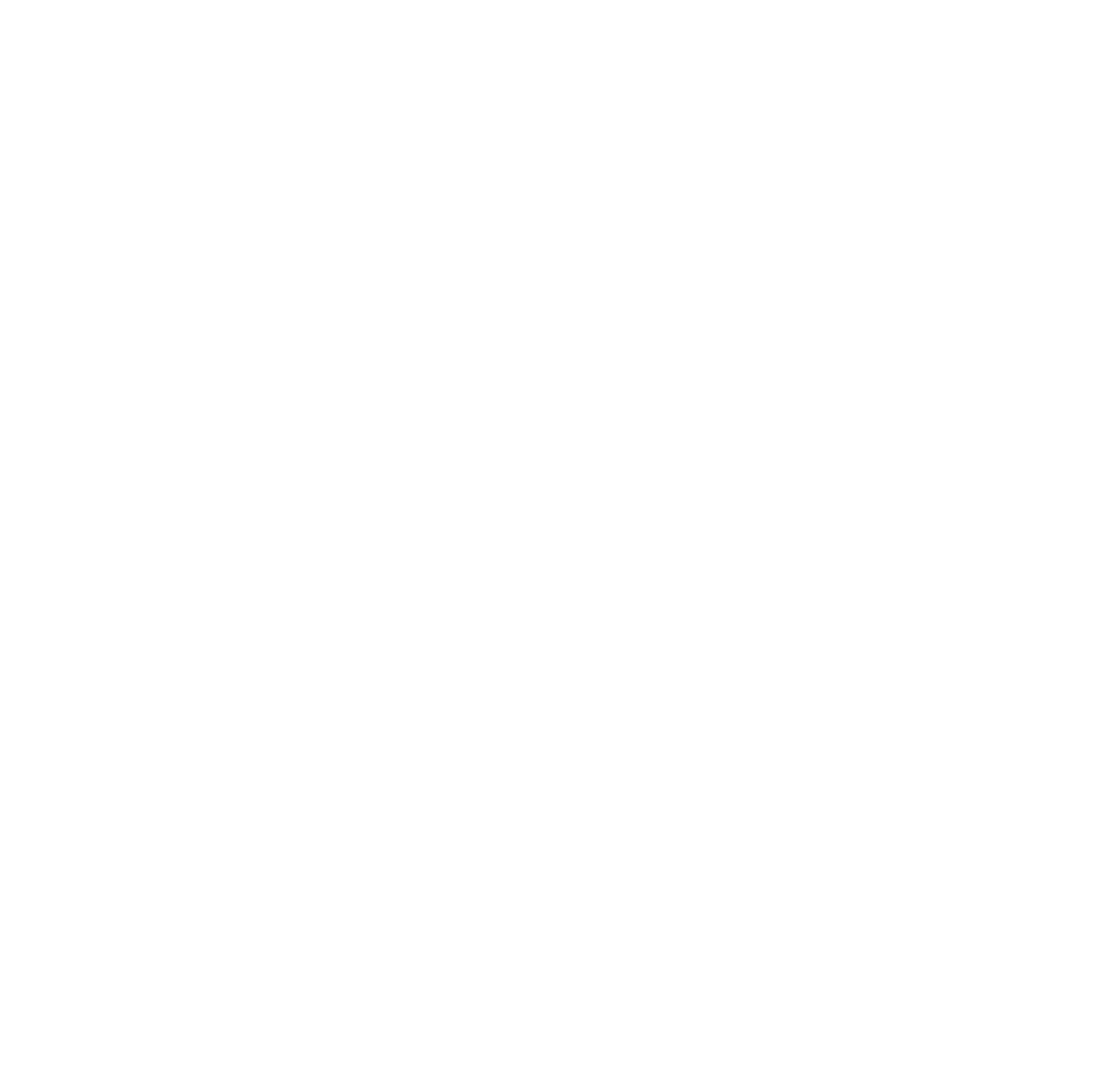

